\title{
Neuroscientist, in Love
}

\author{
Andrew Silverman ${ }^{1}$ \\ Received: 19 February 2019 / Accepted: 14 March 2019 / Published online: 10 April 2019 \\ (C) Academic Psychiatry 2019
}

\section{Artist's Statement}

This poem was inspired by three of my greatest joys: neuroscience, comedy, and my partner. With a dose of humor, and an even healthier helping of neuroscientific reference and analogy, I chose to express my feelings for her in prose. The poem's lyrics are a bit tongue-in-cheek-but not to the extent of a frank hypoglossal palsy, as the underlying sentiment of affection prevails.

Neuroscientist, in love

If I were more poetic,

More articulate,

I would write you a poem

With no science in it

And so, here I am,

Fixed on empiric fact;

It was either the prose herein,

Or submitting an abstract -

But save charts and graphs,

It's difficult to describe this;

My second best try is

Methodically off-rhyming -

Perchance to potentiate

Pair bonding and passion;

A sentiment foretold

Of mirror neuron attraction -
Limbic in your presence,

Not bulbar, but tongue-tied, Stirring Broca's aphasia, And seizing all sulci

Of my left frontal lobe -

Gelastic or drunken,

A sprightly burst projects

To my nucleus accumbens -

Is my love pre-motor,

Or do I have a say?

Organic, chance, or fated,

I hope the feeling stays -

Yet if I were more poetic

And considerably more aesthetic,

I would have written you a ballad

With an edge much more romantic

And, indeed, somewhat sappy,

But that simply is not me -

So I hope your brain's releasing

A healthy dose of dopamine.

\section{Compliance with Ethical Standards}

There are no relevant points to make with regard to compliance with ethical standards.

Financial Disclosures Andrew Silverman reports no disclosures.

Publisher's Note Springer Nature remains neutral with regard to jurisdictional claims in published maps and institutional affiliations.

Andrew Silverman

Andrew.Silverman@yale.edu

1 Yale School of Medicine, New Haven, CT, USA 